\title{
Football Scores on the Big Five Personality Factors across 50 States in the U.S.
}

\section{Xuan Tran*}

University of West Florida, USA

\begin{abstract}
Despite the growing evidence of role personality plays on sport and exercise related behavior, little is known about the influence of personality traits on football players in the U.S. The purpose of this study was to explore the effects of the big five personality traits on football achievements. Extraversion (E), Agreeableness (A), Conscientiousness (C), Neuroticism (N), and Openness (O) traits obtained from 619,397 U.S. respondents in a previous study were used as predictors to state-level football scores in this study. Across 50 states in the U.S., football ranks were positively correlated with state scores on the Big Five personality factors of conscientiousness and agreeableness. However, when applying multiple regression analyses to the prediction model for football ranks based on five independent variables of the Big Five personality factors, only conscientiousness and neuroticism would significantly predict football ranks. Agreeableness correlates with football ranks but does not contribute to the prediction model since agreeableness is collinear with conscientiousness, extraversion, and openness. Neuroticism insignificantly correlates with football ranks but contributes to the prediction because the suppressor effect of conscientiousness by neuroticism has improved its predictor of football ranks. The findings implied that in order to increase high ranks in football practice, selection for athletics would focus on persons with high conscientiousness and neuroticism.
\end{abstract}

Keywords: Conscientiousness; Neuroticism; Extroversion; Agreeableness; Openness; Football

\section{Introduction}

Personality can be defined as the intrinsic organization of an individual's mental world that is stable over time and consistent over situations [1]. The importance of personality as a predictor for behavior performance has been recognized in psychology [2]. Researchers have recently reported the significant effects of personality on sports [3].

What personality type of person is the successful athlete playing football? Are the athletes' personality traits related to their performance on the football field? Using the Profile of Mood States [4-6] had different answers to these questions. It has been reported that no unifying theory of personality and no consensus about which personality dimensions to measure or how to measure them, comparisons of personality were difficult to interpret and, arguably, unreliable [7].

Contemporary research uses the Big Five personality factor model (Extraversion (E), Agreeableness (A), Conscientiousness $(\mathrm{C})$, Neuroticism $(\mathrm{N})$, and Openness $(\mathrm{O})$ ) as a reliable and valid measurement for psychological characteristics [8] based on the three main reasons. First, the five dimensions are rooted in biology [9]. Second, the dimensions are relatively stable throughout life [10], and third, the dimensions are found in several cultures [11].

Most research has focused on the effects of the five personality traits on human behavior. Agreeableness reflects warmth, compassion, cooperativeness, and friendliness. Agreeableness was negatively related to rates of robbery, murder, and property crime [12]. Extraversion is associated with sociability, energy, and health. Different from agreeableness, extraversion reflects sociability and outgoingness more than friendliness and warmth [13]. Conscientiousness reflects dutifulness, responsibility, and self-discipline. Low-conscientiousness individuals are more likely to commit acts of violence and deviance than are high-conscientiousness individuals [12]. Neuroticism reflects anxiety, stress, impulsivity, and emotional instability and is related to antisocial behavior, poor coping, and poor health [12]. Openness reflects curiosity, intellect, and creativity. Open individuals prefer jobs that involve a high degree of abstract and creative thought [12].

Little contemporary research has explored the effects of the five personality traits on football although football is one of the key sports in the United States. This research attempted to explore the influence of football players' personality traits on their achievements. The purpose of this study was thus to examine the effects of neuroticism, extraversion, openness, conscientiousness, and agreeableness on football ranks across 50 states to propose the most effective way to develop a successful football team based on personality traits.

\section{Literature}

Some studies have specifically examined the role of the Big Five in predicting academic performance [14]. Studies have also indicated a positive relationship between conscientiousness and job performance [15]. Piedmont et al. [16] examined the coaches' ratings on their games and found that there were significant correlations between athletic ability and personality. Kovacs [17] reported that conscientiousness and neuroticism have a direct correlation to athletic performance. Extraversion has been found to predict sport performance, particularly in team athletes [18]. Aidman and Schofield [3] reported that Agreeableness and Openness are not correlated with sport performance.

The present study has focused on the five personality traits at state level based on the assumption that psychological characteristics are geographically clustered across the country. There are at least three main reasons for geographic variations on personality across 50 states in the United States. First, the early child rearing practices form psychological characteristics and these practices are shaped by larger societal institutions in which individual lives [19]. Secondly, in the United States the groups of immigrants who chose to leave their homeland possess

*Corresponding author: Xuan Tran, University of West Florida, USA, E-mail xtran@uwf.edu

Received September 22, 2012; Accepted October 26, 2012; Published October 26,2012

Citation: Tran X (2012) Football Scores on the Big Five Personality Factors across 50 States in the U.S. J Sports Med Doping Stud 2:117. doi:10.4172/21610673.1000117

Copyright: (c) 2012 Tran X. This is an open-access article distributed under the terms of the Creative Commons Attribution License, which permits unrestricted use, distribution, and reproduction in any medium, provided the original author and source are credited. 
restricted gene pools of nonrandom samples of personality traits [20]. Finally, there appear geographic variations on personality because the specific personality of social founders may influence regional people's personality traits [21]. Rentfrow et al. [20] examined big five personality traits from over half a million U.S. residents and found that (1) North Dakota was ranked as the state with highest extroversion but Maryland as the state with lowest extroversion; (2) North Dakota was again ranked as the state with the highest agreeableness but Alaska as the state with lowest agreeableness; (3) New Mexico was ranked as the state with the highest conscientiousness but Alaska as the state with the lowest conscientiousness; (4) West Virginia was ranked as the state with the highest neuroticism but Utah as the state with the lowest neuroticism; (5) Washington, D.C. as the district with highest openness but North Dakota as the state with the lowest openness. As a result, fifty U.S. states possessed different levels of big five personality traits [20].

When 50 states are differentiated by their own personality, they will influence athletic performance since the five personality factors (neuroticism, extraversion, openness, conscientiousness, and agreeableness) reflect the core aspects of humans in the sport domain. Therefore, this study hypothesized that there would be significant relationship between football ranks and the big five personality factors across 50 states.

\section{Methods}

\section{Ethical clearance}

According to Rentfrow et al. [20], the personality data were collected as part of an ongoing study of personality involving volunteers assessed over the World Wide Web. The website is a noncommercial, advertisement-free website containing a variety of personality measures. Potential respondents could find out about the site through several channels, including search engines, or unsolicited links on other websites. The data reported in the present research were collected between December 1999 and January 2005. Respondents volunteered to participate in the study by clicking on the personality test icon; they were then presented with a series of questions about their personalities, demographic characteristics, and state of residence. After responding to each item and submitting their responses, participants were presented with a customized personality evaluation based on their responses to all the items [20].

\section{Study design}

The present study explored a model of the relationships between the state-level five personality factors and the state-level football scores. The independent variables are state ranks for each personality dimension, adapted from Rentfrow et al. [20]. The dependent variable is the state ranks for football scores, adapted from Bleacher report [22].

\section{Sampling}

Table 1 provides 51 state ranks for each personality dimension and football score, which were adapted from Rentfrow et al. [20] and the Bleacher report [22].

According to Rentfrow et al. [20], in order to avoid the possibility that respondents may complete a survey multiple times resulting in unreliable and misleading results, the researchers used several criteria to eliminate repeat responders. "First, one question included in the survey asked: "Have you ever previously filled out this particular questionnaire on this site?" If respondents reported completing the questionnaire before, their data were excluded. Second, IP addresses were used to identify repeat responders. If an IP address appeared two or more times within a 1-hr period, all responses were deleted. Third, if an IP address appeared more than once in a time span of more than 1 hour, consecutive responses from the same IP address were matched on several demographic characteristics (gender, age, ethnicity etc.) and eliminated if there was a match. Finally, only respondents who indicated that they lived in the 50 U.S. states or in Washington D.C. were included." [20].

The sample size was 619,397 respondents ( $55 \%$ female). The median age of respondents was 24 years (SD 59.8 years). The sample was comprised of White (80.2\%), African American (4\%), Asian (6.6\%), Latino (4.6\%), and other (4.6\%). The respondents included social class (13.5\%), working class (15.6\%), middle class (42.8\%), and uppermiddle class $(25.7 \%)$ and upper class (2.4\%). Overall, these analyses indicate that our Internet-based sample was generally representative of the population at large [23].

\section{Procedure-data collection and data analysis}

Independent variables were extraversion, agreeableness, conscientiousness, neuroticism, and openness. The five personality traits were obtained from The Big Five Inventory [13]. The Big Five Inventory consists of 44 short statements designed to assess the prototypical traits defining each of the five factor model dimensions based on a 5-point Likert-type rating scale ranging from 1 (disagree strongly) to 5 (agree strongly). The Big Five Inventory scales have shown reliability and validity compared with other five factor model measures at the individual level [24].

Dependent variable was state-level football scores ranked in order for 50 states, which were available online from the Bleacher report [22].

Multiple regression analyses were conducted to find the causative relationship between football scores and five personality traits.

\section{Results}

The means and standard deviations of the data were summarized in table 2 as follows

Table 3 indicates that football ranks were positively associated with scores on the Big Five Inventory factors of Agreeableness $(r=.40$, two-tailed $p=.003)$ and conscientiousness $(r=.42$, two-tailed $p=.002)$ but were not significantly correlated to extraversion, neuroticism, and openness $(r s=.21, .11$, and -.02 , respectively). Using the Spearman rankorder correlation coefficient yielded similar results. Football ranks were positively correlated with Agreeableness and Conscientiousness ( $r s=.40$ and .43 , two tailed $\mathrm{ps}<.001$ ), but were not significantly correlated to Extraversion, Neuroticism, and Openness $(r s=.20, .10$, and -.01 , respectively).

Multiple regression analyses were used to test the causative relationships between football ranks and five personality traits (Extroversion, Agreeableness, Conscientiousness, Neuroticism, and Openness) as illustrated in table 4 as follows:

The result of the regression for football ranks indicated conscientiousness and neuroticism explained $27 \%$ of the variance $(R 2=.27, F(5,44)=3.29, p<.05)$. It was found that conscientiousness and neuroticism predicted football $\operatorname{rank}(\beta s=.37$ and .28 , respectively, ps<.05).

\section{Discussions}

Agreeableness correlates football rankings but does not contribute to the prediction model since Agreeableness is collinear with Conscientiousness, Extraversion, and Openness. Neuroticism does not 
Citation: Tran X (2012) Football Scores on the Big Five Personality Factors across 50 States in the U.S. J Sports Med Doping Stud 2:117. doi:10.4172/2161-0673.1000117

Page 3 of 5

\begin{tabular}{|c|c|c|c|c|c|c|}
\hline State & Football & Extraversion & Agreeableness & Conscientiousness & Neuroticism & Openness \\
\hline Alabama & 1 & 20 & 36 & 36 & 30 & 48 \\
\hline Alaska & 42 & 49 & 51 & 51 & 47 & 49 \\
\hline Arizona & 29 & 24 & 31 & 9 & 45 & 31 \\
\hline Arkansas & 15 & 31 & 41 & 37 & 10 & 27 \\
\hline California & 4 & 38 & 28 & 27 & 37 & 6 \\
\hline Colorado & 32 & 28 & 29 & 15 & 50 & 8 \\
\hline Connecticut & 38 & 33 & 43 & 46 & 15 & 12 \\
\hline Delaware & 42 & 21 & 37 & 34 & 19 & 42 \\
\hline District of Columbia & 42 & 3 & 50 & 40 & 31 & 1 \\
\hline Florida & 2 & 10 & 14 & 8 & 36 & 13 \\
\hline Georgia & 10 & 6 & 8 & 3 & 33 & 20 \\
\hline Hawaii & 37 & 39 & 24 & 49 & 40 & 46 \\
\hline Idaho & 22 & 46 & 39 & 26 & 32 & 30 \\
\hline Illinois & 17 & 9 & 26 & 11 & 20 & 21 \\
\hline Indiana & 8 & 34 & 19 & 14 & 13 & 34 \\
\hline lowa & 26 & 15 & 15 & 33 & 22 & 43 \\
\hline Kansas & 31 & 13 & 17 & 5 & 34 & 38 \\
\hline Kentucky & 27 & 36 & 21 & 19 & 7 & 45 \\
\hline Louisiana & 9 & 30 & 13 & 30 & 8 & 29 \\
\hline Maine & 42 & 11 & 46 & 50 & 12 & 35 \\
\hline Maryland & 33 & 51 & 38 & 35 & 17 & 10 \\
\hline Massachusetts & 34 & 42 & 40 & 43 & 11 & 4 \\
\hline Michigan & 5 & 17 & 11 & 21 & 26 & 36 \\
\hline Minnesota & 35 & 5 & 2 & 22 & 41 & 40 \\
\hline Mississippi & 13 & 19 & 3 & 12 & 4 & 41 \\
\hline Missouri & 25 & 18 & 16 & 10 & 25 & 32 \\
\hline Montana & 42 & 43 & 42 & 29 & 39 & 16 \\
\hline Nebraska & 11 & 4 & 10 & 7 & 44 & 44 \\
\hline Nevada & 39 & 37 & 48 & 24 & 42 & 9 \\
\hline New Hampshire & 42 & 50 & 30 & 44 & 14 & 14 \\
\hline New Jersey & 36 & 14 & 34 & 45 & 5 & 15 \\
\hline New Mexico & 41 & 22 & 33 & 1 & 29 & 23 \\
\hline New York & 30 & 32 & 47 & 42 & 3 & 2 \\
\hline North Carolina & 23 & 35 & 7 & 2 & 24 & 33 \\
\hline North Dakota & 42 & 1 & 1 & 23 & 43 & 51 \\
\hline Ohio & 6 & 25 & 27 & 38 & 9 & 24 \\
\hline Oklahoma & 7 & 27 & 9 & 6 & 27 & 37 \\
\hline Oregon & 21 & 44 & 18 & 31 & 48 & 3 \\
\hline Pennsylvania & 14 & 12 & 35 & 28 & 6 & 25 \\
\hline Rhode Island & 42 & 40 & 45 & 48 & 2 & 28 \\
\hline South Carolina & 12 & 26 & 20 & 16 & 16 & 26 \\
\hline South Dakota & 42 & 7 & 23 & 17 & 49 & 39 \\
\hline Tennessee & 24 & 29 & 6 & 13 & 23 & 19 \\
\hline Texas & 3 & 16 & 25 & 18 & 28 & 17 \\
\hline Utah & 18 & 8 & 4 & 4 & 51 & 18 \\
\hline Vermont & 42 & 47 & 12 & 41 & 18 & 7 \\
\hline Virginia & 16 & 45 & 44 & 39 & 21 & 11 \\
\hline Washington & 28 & 48 & 22 & 25 & 46 & 5 \\
\hline West Virginia & 20 & 23 & 32 & 32 & 1 & 22 \\
\hline Wisconsin & 19 & 2 & 5 & 20 & 35 & 47 \\
\hline Wyoming & 40 & 41 & 49 & 47 & 38 & 50 \\
\hline
\end{tabular}

Table 1: State Rankings for Each Five Factor Personality Dimension and Football Score. (Rentfrow et al. [20] and the Bleacher Report [22])

correlate football rankings but contribute to the prediction because the suppressor effect of Conscientiousness by Neuroticism has improved its predictor of football rankings [25].

Like Kovacs' [17] finding, there is an association between conscientiousness and sport ranking. Conscientiousness is significantly positively correlated with football ranking. Moreover, the present analysis indicated that conscientiousness would predict football rankings. In addition, the study found the football rankings were significantly associated with neuroticism. A state with higher neuroticism would get higher football rankings because neuroticism is a strong predictor for football rankings. In sum, the significance of these relationships may contribute to selection and management of football teams. It also helps forecasting the results of football competition based on the profile of big five personality traits. In order to increase high ranks in football practice, selection for athletics would focus on 


\begin{tabular}{|l|l|l|}
\hline Average of 50-state data & Mean & Std.Deviation \\
\hline Football rank & 24.78 & 13.54 \\
\hline Extroversion rank & 26.10 & 14.99 \\
\hline Agreeableness rank & 25.78 & 14.93 \\
\hline Conscientiousness rank & 25.84 & 14.92 \\
\hline Neuroticism rank & 26.14 & 14.98 \\
\hline Openness rank & 25.68 & 14.83 \\
\hline
\end{tabular}

Table 2: Descriptive Statistics of Football and the Big Five Personality Traits Enrollment in local colleges.

\begin{tabular}{|l|l|l|l|l|l|l|}
\hline & $(1)$ & $(2)$ & $(3)$ & $(4)$ & $(5)$ & $(6)$ \\
\hline 1. Football rank & & .22 & $.39^{* *}$ & $.41^{* *}$ & .12 & -.05 \\
\hline 2. Extroversion rank & & & $.43^{* *}$ & $.44^{* *}$ & -.12 & $-.31^{*}$ \\
\hline 3. Agreeableness rank & & & & $.65^{\star *}$ & -.18 & $-.30^{*}$ \\
\hline 4. Conscientiousness rank & & & & & $-.32^{*}$ & -.12 \\
\hline 5. Neuroticism rank & & & & & & .10 \\
\hline 6. Openness rank & & & & & & \\
\hline
\end{tabular}

$\left({ }^{* *}\right)$ Correlation is significant at 0.01 levels (1-tailed)

$\left({ }^{*}\right)$ Correlation is significant at 0.05 levels (1-tailed)

Table 3: Pearson Correlations of Football Rank, Extroversion Rank, Agreeableness Rank, Conscientiousness Rank, Neuroticism Rank, and Openness Rank.

persons with high Conscientiousness and Neuroticism. Future research might also find the model of these relationships useful when expanding athletic departments.

Since low-Conscientiousness individuals are more likely to commit acts of violence and deviance than are high-Conscientiousness individuals [12], football players with low conscientiousness may be likely to commit doping or other deviant behavior. Conscientiousness reflects the degree to which football players prefer systematic and focused tasks and clearly defined rules and regulations so conscientious individuals tend to engage in health promoting behavior and live long healthy lives, which is consistent with previous research [26]. Conscientiousness was negatively related to spending time in a bar and entertaining guests at home [20] so conscientious football players were not related to social involvement. Rentfrow et al. [20] also reported that large proportions of computer scientists and mathematicians in high Conscientiousness states and more artists and entertainers are in low Conscientiousness states.

Neuroticism reflects anxiety, stress, impulsivity, and emotional instability. Table 4 indicates that Neuroticism is a significant predictor in the model although the correlation between Neuroticism and Football scores is not significant. The reason for this is Neuroticism is a suppressor. According to Cohen et al. [25], a suppressor that is uncorrelated with $\mathrm{Y}$ may be significant in a multiple regression model. The suppressor effect of Conscientiousness by Neuroticism has improved its predictor of football rankings. A football player with high Neuroticism may take a risk to attain the goal by doping or antisocial behavior; however, the direction of these relationships changed when controlling for urbanization and income [20]. The research showing inverse relationships between Neuroticism and longevity and Neuroticism is negatively related social involvement [12,27].

Agreeableness reflects warmth, compassion, cooperativeness, and friendliness at the individual level. Agreeableness was correlated with football scores but it did not predict football scores since football players with high agreeableness were positively associated with activities that promote tight social relations so it correlates with the football scores when the players help others in their team but in order to attain the goal, the cooperativeness should be replaced by competition.

An increase in conscientiousness is associated with an increase

\begin{tabular}{|l|c|c|c|c|c|}
\hline${ }^{*}$ Predictor & C & E & A & O & N \\
\hline$r(p)$ & $.43(.00)$ & $.20(.15)$ & $.40(.00)$ & $-.01(.91)$ & $.10(.44)$ \\
\hline$\beta(p)$ & $.36(.05)$ & $.00(.96)$ & $.22(.20)$ & $.05(.68)$ & $.27(.05)$ \\
\hline
\end{tabular}

Predictors: C: Conscientiousness; E: Extraversion; A: Agreeableness; O Openness; N: Neuroticism

Dependent Variable: Football rank

Table 4: Spearman's rho Bivariate and Multivariate Contributions-DV=Football ranks.

in football ranking. Moreover, the present analysis indicated that conscientiousness would predict football ranks. In addition, the study found the football ranks were significantly associated with neuroticism. A state with higher neuroticism would get higher football ranks and neuroticism is a strong predictor for football ranking. In sum, the significance of these relationships may contribute to selection and management of football teams. It also helps forecasting the results of football competition based on the profile of big five personality traits. In order to increase high ranks in football practice, selection for athletics would focus on persons with high conscientiousness and neuroticism. Future research might also find the model of these relationships useful when expanding athletic departments.

\section{References}

1. Piedmont RL (1998) The Revised NEO Personality Inventory: Clinical and Research Applications. Springer, New York.

2. Sternberg RJ (2000) Handbook of intelligence. New York: Cambridge University Press.

3. Aidman E, Schofield G (2004) Personality and Individual Differences in Sport (2ndedn), Sport psychology: theory, applications and issues Wiley, Milton, Australia.

4. McNair DM, Lorr M, Droppleman LF (1981) Profile of Mood States manual. Educational and Industrial Testing Service, San Diego, CA.

5. Newby RW, Simpson S (1991) Personality profile of nonscholarship college football players. Percept Mot Skills 73: 1083-1089.

6. Leunes A, Nation JR (1982) Saturday's heroes: a psychological portrait of college Football players. Journal of Sport Behavior 5: 139-149.

7. Levine RA (2001) Culture and personality studies, 1918-1960: myth and history. J Pers 69: 803-818.

8. Costa PT, McCrae RR (1992) The Revised NEO Personality Inventory (NEO PI-R). Odessa, FL: Psychological Assessment Resources.

9. Jang KL, McCrae RR, Angleitner A, Riemann R, Livesley WJ (1998) Heritability of facet-level traits in a cross-cultural twin sample: support for a hierarchica model of personality. J Pers Soc Psychol 74: 1556-1565.

10. McCrae RR, Costa PT Jr (2003) Personality in Adulthood: A Five-Factor Theory perspective. (2ndedn), Guilford Press, New York, USA.

11. Benet-Martinez V, John OP (2000) Toward the Development of QuasiIndigenous Personality Constructs. American Behavioral Scientist 44: 141-157.

12. Ozer DJ, Benet-Martínez V (2006) Personality and the prediction of consequential outcomes. Annu Rev Psychol 57: 401-421.

13. John OP, Srivastava S (1999) The Big Five Trait taxonomy: History, measurement, and theoretical perspectives. In LA Pervin, OP John (Eds.) Handbook of personality: Theory and research (2nd ed., pp. 102-139). New York: Guilford.

14. Busato VV, Prins FJ, Elshout JJ, Hamaker C (2000) Intellectual ability, learning style, personality, achievement motivation and academic success of psychology students in higher education. Pers Indiv Differ 29: 1057-1068.

15. Salgado JF (1997) The Five Factor Model of personality and job performance in the European Community. J Appl Psychol 82: 30-43.

16. Piedmont RL, Hill DC, Blanco S (1999) Predicting athletic performance using the five-factor model of personality. Pers Indiv Differ 27: 769-777.

17. Kovacs M (2008) Relationship between personality and collegiate tennis rankings. Medicine and Science in Sports and Exercise 40: 209-210. 
Citation: Tran X (2012) Football Scores on the Big Five Personality Factors across 50 States in the U.S. J Sports Med Doping Stud 2:117. doi:10.4172/2161-0673.1000117

18. Taylor DM, Doria JR (1981) Self-serving and group-serving biases in attribution J Soc Psychol 113: 201-211.

19. Peabody D (1988) National characteristics. Cambridge, United Kingdom: Cambridge University Press and Maison des Sciences de l'Homme.

20. Rentfrow P, Gosling S, Potter J (2008) A theory of the emergence, persistence, and expression of geographic variation in psychological characteristics. Perspective on Psychological Science 3: 339-369.

21. Kitayama S, Ishii K, Imada T, Takemura K, Ramaswamy J (2006) Voluntary settlement and the spirit of independence: evidence from Japan's "Northern frontier". J Pers Soc Psychol 91: 369-384.

22. Vasta D (2012) Power Ranking All 50 States by Their College Football Teams.

23. Gosling SD, Vazire S, Srivastava S, John OP (2004) Should we trust web- based studies? A comparative analysis of six preconceptions about internet questionnaires. Am Psychol 59: 93-104.

24. Benet-Martínez V, John OP (1998) Los Cinco Grandes across cultures and ethnic groups: multitrait multimethod analyses of the Big Five in Spanish and English. J Pers Soc Psychol 75: 729-750.

25. Cohen J, West SG, Aiken L, Cohen P (2003) Applied multiple regression/ correlation analysis for the behavioral sciences, (3rdedn). Mahwah, NJ. Erlbaum Associates.

26. Bogg T, Roberts BW (2004) Conscientiousness and health-related behaviors: a meta-analysis of the leading behavioral contributors to mortality. Psychol Bull 130: 887-919.

27. Roberts BW, Kuncel NR, Shiner R, Caspi A, Goldberg LR (2007) The Power of personality: The comparative validity of personality traits, socioeconomic status, and cognitive ability for predicting important life outcomes. Perspective Psych Sci 2: 313-345. 